\title{
How Ambient Cues Facilitate Political Segregation
}

\author{
Matt Motyl \\ New York University \\ JP Prims \\ University of Illinois at Chicago \\ Ravi Iyer \\ Facebook
}

Final manuscript as submitted and accepted at Personality and Social Psychology Bulletin.

Please cite as:

Motyl, M., Prims, J., \& Iyer, R. (accepted). How ambient cues facilitate political segregation. Personality and Social Psychology Bulletin. 


\begin{abstract}
People increasingly self-segregating into politically homogenous communities. How they do this remains unclear. We propose that people use ambient cues correlated with political values to infer whether they would like to live in those communities. We test this hypothesis in 5 studies. In Studies $1(\mathrm{~N}=3543)$ and $2(\mathrm{~N}=5609)$, participants rated community cues; liberals and conservatives' preferences differed. In Studies 3a $(\mathrm{N}=1643)$ and $3 b(\mathrm{~N}=1840)$, participants read about communities with liberal or conservative cues. Even without explicit information about the communities' politics, participants preferred communities with politically-congenial cues. In Study $4(\mathrm{~N}=282)$, participants preferred politically-congenial communities, and wanted to leave politically-uncongenial communities. In Study $5(\mathrm{~N}=370)$, people selectively navigated their communities in a politically-congenial way. These studies suggest that peoples' perceptions of communities can be shaped by subtle, not necessarily political, cues that may facilitate growing political segregation.

Keywords: ideology, migration, social ecology, politics, residential mobility
\end{abstract}




\section{How Ambient Cues Facilitate Political Segregation}

The United States of America is an increasingly divided nation. Polarization in Congress and among citizens has reached unprecedented heights (Abramowitz, 2016; Iyengar, Sood, \& Lelkes, 2012; McCarty, Poole, \& Rosenthal, 2016). One factor contributing to this division is geographic political segregation, where Americans live in distinct politically homogeneous communities (Bishop \& Cushing, 2008; McDonald, 2011; Motyl, 2016). People in homogeneous groups often polarize and become more extreme in their beliefs (Mackie, 1986; Keating, van Boven, \& Judd, 2016; Sunstein, 2002). No empirical work to date addresses specifically how people sort themselves into politically distinct and homogeneous communities. This tendency is mysterious considering the generally low levels of political knowledge among Americans (Delli Carpini, 2000; Delli Carpini \& Keeter, 1992; Frimer, Skitka, \& Motyl, 2017). This set of studies seeks to understand how people navigate their world in ways that fosters political segregation, even without explicit knowledge of communities' political leanings.

\section{Self-Segregation and Identity Enclaves}

The tendency to segregate into groups or locations with similar others, or to create homogeneous identity enclaves, appears in education, personality, race, religion, socioeconomic status, values, and more (McPherson, Smith-Lovin, \& Cook, 2001). These communities of similar others may form because people are generally attracted to similar others, and repelled from dissimilar others (Byrne, Clore, \& Smeaton, 1986; Rosenbaum, 1986). As these two processes generate greater similarity within groups than between groups, we hereafter refer to both of them as self-segregation.

Identifying similar and dissimilar others is sometimes easy. If there are visible cues of group membership, observers can see where to congregate with similar others, and where to 
avoid to distance themselves from dissimilar others (MacKinnon, Jordan, \& Wilson, 2011). Informal racial segregation emerges in public spaces, like beaches and classrooms (e.g., Dixon \& Durrheim, 2003; Purdie-Vaughns, Steele, Davies, Ditlmann, \& Crosby, 2008). Other characteristics, like socioeconomic status, can be inferred from people's clothing and belongings. People tend to occupy spaces within university communities where those around them come from similar socioeconomic backgrounds, despite diversity of socioeconomic backgrounds at their universities (Trawalter, Hoffman, \& Palmer, in press). Visual cues make self-segregation relatively easy. Some identities, though, may not have obvious visible cues that allow for straightforward self-segregation. Yet, people still manage to self-segregate along these less obviously distinct lines. Londoners tend to live in specific neighborhoods where their neighbors share similar personality traits as them, and Americans with different personality traits also cluster in different regions (e.g., Jokela, Bleidorn, Lamb, Gosling, \& Rentfrow, 2015; Rentfrow, Gosling, \& Potter, 2008). Beyond holding similar personality characteristics as one's neighbors, people's personality traits may lead them to migrate to locales where they are likely to find similar others (Jokela, 2009; Jokela, Elovainio, Kivimaki, \& Keltikangas-Jarvinen, 2008). In cases like personality where the visible cues are less obvious, observers must rely on other cues. People with different personality characteristics convey their personality through ambient cues in their environments. For example, people higher on conscientiousness tend to have desks that are more organized, more books on their shelves, and better lighting. Outside observers are reasonably accurate in inferring a person's personality based on the ambient cues in their physical space (Gosling, Ko, Mannarelli, \& Morris, 2002). This suggests that, while visible cues of some identity characteristics are less obvious, people can categorize others based on the ambient cues in those others' environments. 
Over time, the residents of these communities may erect identity-congenial features that appeal to similar others. Communities with a population that is more conscientious than average may build more libraries and bookstores, whereas communities with a population that is more extraverted than average may build more public parks and bars. Organizations may convey their commitment to diversity by displaying signs and brochures (e.g., Purdie-Vaughns et al., 2008). These identity signals may repel some individuals from particular communities. Non-Christians report less subjective well-being and less belonging in spaces containing Christian symbols of crucifixes, nativity scenes, and "Merry Christmas" messages (Bilewicz \& Klebaniuk, 2013; Ribak-Rosenthal \& Russell, 1994; Schmitt, Hung, Davies, \& Wright, 2010).

Residents may enact laws that make communities more appealing for some people than others. Within the United States, laws pertaining to sexual minorities varied greatly. More traditional states banned non-traditional marriages between sexual minorities, and sexual minorities living in these states felt they did not belong, and expressed greater desire to migrate to other states (e.g., Lick, Tornello, Riskind, Schmidt, \& Patterson, 2012). Through the accumulation of identity-relevant amenities and policies, communities may become appealing to people with some identities and repelling to people with other identities. As ambient identity cues become more pervasive, it becomes easier for people to navigate their environment in ways that foster greater segregation.

\section{Political Segregation and Identity Ambience}

Americans have increasingly segregated themselves into political enclaves where they have decreasing contact with politically dissimilar others (Bishop \& Cushing, 2008). It remains unclear how this happens, and whether people use political identity-relevant ambient cues facilitate this process. To date, most of the explanations for how this political segregation 
emerges is speculative. Motyl and colleagues (2014) proposed that people intuit a sense of belonging in places that share their political views, and a lack of belonging in places that hold differing political views, and that this motivates a desire to migrate to more politically-congenial communities. In contrast, Mummalo and Nall (2017) argue that this sorting is due primarily to people wanting to live in communities with certain qualities, like order and public transportation, which may be incidentally related to politics, but politics is not driving the segregation. Others argue for a middle ground, where people with different political identities desire different community features, and that these features attract people with certain political leanings, and repel people with other political leanings (Gimpel \& Hui, 2015; Gimpel \& Hui, 2017). Political identity relevant cues in communities may convey political ambiance that attracts politically similar others and repels politically dissimilar others, resulting in political segregation.

During election years, neighborhoods may be rife with explicit political cues including bumper stickers, yard signs, and advertisements signaling the political leanings of its residents. Most of the time, though, such explicit cues do not exist. Nonetheless, people with different political identities construct different living spaces and workplaces (Carney, Jost, Gosling, \& Potter, 2008). Conservatives have more sports décor and calendars in their rooms, and have more conventional offices. Liberals have a larger variety of books and music, more art supplies, and more distinctive offices (Carney, et al., 2008). These individual differences across political identities scale up to their broader communities. Liberals prefer smaller homes in dense, walkable communities with more art museums and theaters, while conservatives prefer larger homes in smaller towns with more congenial religious organizations nearby (Pew Research Center, 2014). In addition to these self-reported different community preferences that differ on the basis of political identity, communities that exhibit these features tend to have more residents 
who vote for the candidate most reflective of that political identity (Chinni \& Gimpel, 2011;

Gimpel \& Schuknecht, 2009). Liberal and conservative communities may convey political

ambiance, which makes them appealing to politically similar others and repulsive to politically dissimilar others.

\section{The Current Research}

This research examines how community characteristics may make communities attractive to people with one political leaning, and repulsive to people with another. In Study 1, we ask liberals and conservatives to select important community characteristics from a list. In Study 2, we expand upon Study 1 by asking participants to evaluate the desirability of different characteristics, and how those characteristics affect the appeal of a hypothetical community. In Studies $3 \mathrm{a}$ and $3 \mathrm{~b}$, we examine whether community characteristics inform people of the political leanings of communities. In Study 4, we test if community characteristics are associated with desire to migrate. In Study 5, we conducted a field study to examine whether liberals and conservatives selectively navigate to politically-congenial spaces within larger communities. All data and materials are available on the Open Science Framework (https://osf.io/rds69/)

\section{Study 1: Assessing Community Preferences}

In Study 1, we examine what liberals and conservatives desire in their ideal community. We presented them with a list of numerous community characteristics, and asked participants to select the characteristics most important to them in an ideal community.

\section{Method}

Participants. Given the exploratory nature of this study, and the sometimes small effect sizes in studies of political differences, we used data from all 3543 participants who completed the "Ideal Community Task" on YourMorals.org. During the registration process, participants 
completed a demographics questionnaire. Then, participants could choose to participate in various studies. All subsequent YourMorals.org studies recruited participants and gathered demographics the same way. Political orientation was assessed using a 7-point scale ranging from 1 (Very Liberal) to 7 (Very Conservative). Two thousand four hundred and twenty participants chose one of the liberal options (1-3), 702 chose one of the conservative options (57, and 421 identified as moderate (4). The analyses are based on the continuous 7-point political orientation response. One thousand four hundred and forty-eight were women, and 2095 were men $^{1}$. Participants' ages ranged from 18 to $84(M=38.18, S D=16.08)$. Participants received feedback on how their responses compared to others.

Materials and Procedure. For the "Ideal Community Task," participants viewed a list of 48 community characteristics, generated mostly from Gimpel and Chinni's (2010) data on different types of communities in the United States. The characteristics' order was randomized. Participants picked the 10 most important characteristics that they would want in their ideal community. Once they selected 10 characteristics, they had 100 "importance points" to allocate. Characteristics that were more important to them received more points, and characteristics that were less important received less points. All characteristics are displayed in Table 1.

\section{Results}

Tables 1 and 2 display correlations between political orientation and the importance points allocated to all 48 characteristics. Most participants, regardless of political orientation, preferred safe communities with good job opportunities. Liberals and conservatives diverged in their evaluations of other characteristics. Liberals preferred communities with more liberals, public transportation, ethnic diversity, and vibrant arts scenes. Conservatives preferred

\footnotetext{
${ }^{1}$ These numbers represent the participants' sex. The YourMorals survey did not request information on their gender.
} 
communities with more conservatives, patriotism, an active religious community, and many churches.

\section{Discussion}

In this study political leanings correlated with community characteristics. Liberal participants identified political liberalism, ethnic diversity, public transportation, and a vibrant arts scene as important characteristics of their ideal community. In contrast, conservative participants identified political conservatism, patriotism, many churches, and ruralism as important characteristics of their ideal community. Differences emerged not just for characteristics directly related to culture war issues, but also characteristics that are not inherently political like having good nightlife (preferred by liberals) or easy parking (preferred by conservatives). These characteristics may affect prospective residents' evaluation of those communities, and their decision to approach or avoid those communities. Overall, liberals chose a wider variety of characteristics than conservatives, though it is not clear why. It may be that we selected more characteristics that tend to be preferred liberals, or that liberals agree on more community characteristics than conservatives.

Study 1 was consistent with our predictions, but was limited by participants' inability to evaluate all characteristics. Some characteristics preferred by one side were rarely rated by the other. The average point-biserial correlation between political orientation and choosing a characteristic was $r=.14$. 


\section{Table 1}

Correlations between political orientation and characteristic importance, for items rated most often by liberals

\begin{tabular}{|c|c|c|c|}
\hline Characteristic & Chosen r [95\% CI] & n & r $[95 \% \mathrm{CI}]$ \\
\hline \multicolumn{4}{|l|}{ Overt Political Cues } \\
\hline most people are liberal & $-.37[-.40,-.34]$ & 818 & $-.33[-.36,-.30]$ \\
\hline active gay community & $-.17[-.20,-.14]$ & 250 & $-.15[-.18,-.11]$ \\
\hline \multicolumn{4}{|l|}{ Subtle Physical Cues } \\
\hline public transportation & $-.26[-.29,-.23]$ & 1218 & $-.23[-.26,-.20]$ \\
\hline lots of vegetarian restaurants & $-.15[-.18,-.12]$ & 224 & $-.13[-.16,-.09]$ \\
\hline affordable housing & $-.13[-.16,-.10]$ & 1344 & $-.12[-.15,-.09]$ \\
\hline major university & $-.12[-.16,-.10]$ & 922 & $-.12[-.15,-.09]$ \\
\hline pedestrian friendly & $-.12[-.15,-.09]$ & 1014 & $-.11[-.14,-.08]$ \\
\hline bike friendly & $-.10[-.13,-.07]$ & 551 & $-.11[-.14,-.07]$ \\
\hline urban community & $-.10[-.13,-.07]$ & 416 & $-.10[-.13,-.06]$ \\
\hline clean air/water & $-.08[-.12,-.05]$ & 2239 & $-.09[-.13,-.07]$ \\
\hline many independent retail stores & $-.07[-.11,-.04]$ & 625 & $-.07[-.10,-.03]$ \\
\hline feels like a big city & $-.07[-.10,-.04]$ & 381 & $-.06[-.09,-.03]$ \\
\hline good medical care & $-.07[-.10,-.04]$ & 1778 & $-.06[-.09,-.03]$ \\
\hline close to nature & $-.06[-.09,-.02]$ & 1551 & $-.06[-.10,-.03]$ \\
\hline few churches & $-.06[-.09,-.03]$ & 155 & $-.06[-.09,-.03]$ \\
\hline good nightlife/bars & $-.05[-.08,-.01]$ & 461 & $-.04[-.07,-.005]$ \\
\hline many ethnic restaurants & $-.01[-.04,-.02]$ & 789 & $-.08[-.11,-.04]$ \\
\hline \multicolumn{4}{|l|}{ Demographic Cues } \\
\hline ethnically diverse & $-.27[-.30,-.24]$ & 1133 & $-.23[-.26,-.19]$ \\
\hline many atheists & $-.19[-.22,-.16]$ & 394 & $-.17[-.20,-.13]$ \\
\hline well educated residents & $-.13[-.16,-.10]$ & 1955 & $-.14[-.17,-.10]$ \\
\hline large scientific community & $-.12[-.16,-.09]$ & 663 & $-.11[-.14,-.07]$ \\
\hline economically diverse community & $-.03[-.07,-.0003]$ & 546 & $-.05[-.08,-.02]$ \\
\hline many young people & $-.02[-.06,-.01]$ & 433 & $-.02[-.06,-.01]$ \\
\hline vibrant arts community & $-.01[-.04, .02]$ & 1260 & $-.20[-.23,-.17]$ \\
\hline people share my values ${ }^{2}$ & $-.01[-.04, .02]$ & 895 & $.12[.09, .15]$ \\
\hline
\end{tabular}

\footnotetext{
${ }^{2}$ Both liberals and conservatives were equally likely to pick "people share my values" as a desirable characteristic, though conservatives allocated this characteristic more importance points. Unfortunately, it is not clear if participants interpreted this as political values, moral values, another type of values, or some mix.
} 
Note. Participants only rated their top 10 community characteristics. Negative correlations indicate that more liberal people placed higher importance on a characteristic, while positive correlations indicate that more conservative people placed higher importance on a characteristic. The first column shows the point-biserial correlation between selecting the item and participant political orientation. The second column shows the number of participants who rated that item, and the third column shows the correlation between ratings for that item and political orientation. Correlation coefficients are not adjusted for demographic variables. When controlling for age, importance is not correlated with political orientation for good nightlife/bars and having many young people. Correlation coefficients adjusting for age are available in the supplementary materials.

\section{Table 2}

Correlations between political ideology and characteristic importance, for items rated most often by conservatives

\begin{tabular}{llll}
\hline Characteristic & Chosen r [95\% CI] & $\mathbf{n}$ & $\mathbf{r}[\mathbf{9 5 \%} \mathbf{C I}]$ \\
\hline $\begin{array}{l}\text { Overt Political Cues } \\
\text { most people are conservative }\end{array}$ & $.45[.43, .48]$ & 188 & $.40[.37, .42]$ \\
& & & \\
Subtle Physical Cues & & & \\
patriotic community & $.43[.41, .46]$ & 245 & $.38[.35, .40]$ \\
active religious community & $.34[.31, .36]$ & 334 & $.31[.28, .34]$ \\
family friendly & $.31[.28, .34]$ & 779 & $.28[.25, .31]$ \\
many churches & $.27[.24, .30]$ & 156 & $.25[.22, .28]$ \\
good police/fire protection & $.21[.18, .24]$ & 936 & $.21[.18, .24]$ \\
feels like a small town & $.20[.17, .23]$ & 555 & $.18[.15, .21]$ \\
rural community & $.17[.14, .20]$ & 280 & $.15[.11, .18]$ \\
safety & $.17[.14, .20]$ & 1713 & $.16[.13, .19]$ \\
military community & $.17[.13, .19]$ & 56 & $.12[.90, .15]$ \\
clean streets & $.15[.12, .19]$ & 840 & $.13[.10, .17]$ \\
not too noisy & $.14[.11, .18]$ & 802 & $.11[.08, .14]$ \\
many chain stores & $.11[.08, .14]$ & 68 & $.08[.05, .11]$ \\
easy parking & $.11[.08, .15]$ & 254 & $.12[.09, .15]$ \\
good job opportunities & $.08[.04, .11]$ & 1838 & $.09[.05, .12]$ \\
\hline
\end{tabular}




\begin{tabular}{llll}
\hline good professional sports teams & $.06[.03, .09]$ & 109 & $.04[.01, .08]$ \\
large open spaces & $.05[.02, .08]$ & 827 & $.03[.002, .07]$ \\
good K 12 schools & $.05[.02, .08]$ & 1190 & $.05[.01, .08]$ \\
& & & \\
Demographic Cues & & & \\
wealthy community & $.16[.13, .20]$ & 191 & $.14[.11, .18]$ \\
friendly neighbors & $.13[.09, .16]$ & 1438 & $.11[.08, .15]$ \\
many older people & $.03[.001, .07]$ & 54 & $.02[-.006, .06]$ \\
\hline
\end{tabular}

Note. Participants only rated their top 10 community characteristics. Negative correlations indicate that more liberal people placed higher importance on a characteristic, while positive correlations indicate that more conservative people placed higher importance on a characteristic. The first column shows the point-biserial correlation between selecting the item, and participant political orientation, the second column shows the number of participants who rated that item, and the third column shows the correlation between ratings for that item and political orientation. Correlation coefficients are not adjusted for demographic variables. When controlling for age, importance is not correlated with political orientation for large open spaces and having many older people. Correlation coefficients adjusting for age are available in the supplementary materials.

\section{Study 2: Evaluating Ideological Ambience Via Community Characteristics}

In Study 1, participants chose their top 10 characteristics, and allocated importance points to those 10 items. Study 2 includes a shorter list of the more politically-divided characteristics, and asks participants to evaluate how these characteristics would affect their evaluation of a community.

\section{Method}

Participants. Participants in this study were 5,609 people who reside in the United States (2670 women, 2938 men, 1 unreported) and visited YourMorals.org. Our sample size consisted of all people who selected the "Community Preferences Questionnaire" and provided a political 
orientation. Political orientation ranged from Very Liberal to Very Conservative (1117 Very Liberal, 2019 Liberal, 829 Slightly Liberal, 709 Moderate, 349 Slightly Conservative, 414 Conservative, 172 Very Conservative).

Materials and Procedure. The Community Cues Questionnaire consisted of 32 different cues from Study 1, some with lightly edited working to fit with the new questionnaire design (e.g., "Most People Are Liberal” became "Majority Liberal”). The characteristics' order was randomized. The instructions for the questionnaire were as follows:

Suppose you were offered a job that would require you to move. The job is slightly better than your current job, or any other job offer you think you could get, in terms of pay, benefits, job security, and the desirability of the work.

Suppose that it was a time in your life when you could easily move, if you wanted to, so you begin to read about the city to which the new job would take you. You learn a lot of facts about the new city. How would each of the following facts influence your desire to move? Would it make you more or less likely to take the new job?

Please evaluate each fact separately. Just think about whether that fact makes the city more or less appealing.

Participants rated each cue on a scale ranging from 1 (much less appealing) to 5 (much more appealing). When finished, participants received feedback on how their evaluations compared to other visitors of YourMorals.org.

\section{Results}

Of the 32 cues, 29 significantly correlated with political orientation (see Table 3 for descriptive and inferential statistics). 
Conservatism most strongly correlated with a preference for teaching Creationism in schools, many gun stores, a primarily Caucasian community, and Protestant churches. Liberalism most strongly correlated with a preference for an active gay community, hybrid cars, racial diversity, and organic food stores.

Three characteristics did not correlate with political ideology. Liberals and conservatives were equally enthusiastic about white-collar workers, basketball, and many clothing stores. 
Table 3

Community characteristic ratings by political orientation

\begin{tabular}{|c|c|c|c|c|c|}
\hline \multirow[b]{2}{*}{ Community Cue $^{\mathrm{a}}$} & \multicolumn{2}{|c|}{ Political Orientation } & \multirow[b]{2}{*}{$M_{\text {diff }}$} & \multirow[b]{2}{*}{$S D$} & \multirow[b]{2}{*}{ Pearson's $r[95 \% \mathrm{CI}]^{\mathrm{c}}$} \\
\hline & Liberal $^{\mathrm{b}}$ & Conservative $^{\mathrm{b}}$ & & & \\
\hline \multicolumn{6}{|l|}{ Overt Political Cues } \\
\hline Creationism in Schools & 1.30 & 2.80 & -1.50 & 1.13 & $.50[.48, .52]$ \\
\hline Active Gay Community & 3.84 & 2.36 & 1.48 & 1.14 & $-.60[-.61,-.58]$ \\
\hline Majority Liberals & 4.20 & 1.72 & 2.48 & 1.32 & $-.74[-.75,-.73]$ \\
\hline Majority Conservatives & 1.42 & $3.47-$. & -2.05 & 1.10 & $.75[.74, .76]$ \\
\hline Many Protestant Churches & 2.34 & 3.41 & -1.07 & 1.06 & $.39[.36, .41]$ \\
\hline \multicolumn{6}{|l|}{ Physical Cues } \\
\hline Many Gun Stores & 1.70 & 3.23 & -1.53 & 1.29 & $.53[.51, .55]$ \\
\hline Military Base & 2.16 & 3.21 & -1.05 & 1.14 & $.39[.37, .42]$ \\
\hline SUVs & 2.07 & 2.90 & -0.83 & 0.91 & $.40[.38, .42]$ \\
\hline Hybrid Cars & 3.67 & 2.90 & 0.77 & 0.97 & $-.48[-.50,-.45]$ \\
\hline Many Bicyclists & 4.01 & 3.13 & 0.88 & 1.00 & $-.32[-.35,-.30]$ \\
\hline Organic Food Stores & 4.05 & 3.49 & 0.56 & 0.91 & $-.30[-.31,-.26]$ \\
\hline Art-walk & 4.22 & 3.64 & 0.58 & 0.82 & $-.30[-.32,-.27]$ \\
\hline Large University & 4.23 & 3.60 & 0.63 & 1.02 & $-.30[-.32,-.27]$ \\
\hline Wal-Mart & 1.85 & 2.30 & -0.45 & 0.96 & $.31[.28, .33]$ \\
\hline Fast Food & 2.30 & 2.60 & -0.30 & 0.92 & $.20[.17, .22]$ \\
\hline Many Supermarkets & 2.13 & 2.46 & -0.33 & 0.91 & $.27[.25, .30]$ \\
\hline Retail Chain Stores & 2.90 & 3.33 & -0.43 & 0.90 & $.27[.24, .29]$ \\
\hline Barbecue & 3.29 & 3.51 & -0.22 & 0.97 & $.12[.09, .14]$ \\
\hline Many Restaurants & 4.30 & 4.10 & 0.20 & 0.80 & $-.10[-.13,-.08]$ \\
\hline Many Bookstores & 4.34 & 4.36 & -0.02 & 0.74 & $-.24[-.27,-.22]$ \\
\hline Clothing Stores & 3.39 & 3.54 & -0.15 & 0.84 & $.02[-.003, .05]$ \\
\hline Competitive Team Sports & 2.39 & 3.05 & -0.66 & 1.07 & $.29[.26, .31]$ \\
\hline Basketball & 3.01 & 2.79 & 0.22 & 0.78 & $.02[-.01, .04]$ \\
\hline \multicolumn{6}{|l|}{ Demographic Cues } \\
\hline Minority White & 3.55 & 2.67 & 0.88 & 0.96 & $-.34[-.37,-.32]$ \\
\hline Vast Majority White & 2.18 & 3.62 & -1.44 & 1.18 & $.40[.37, .42]$ \\
\hline Condos & 2.79 & 2.15 & 0.64 & 0.82 & $-.16[-.18,-.13]$ \\
\hline Single-family Houses & 3.13 & 4.10 & -0.97 & 1.01 & $.31[.29, .33]$ \\
\hline Families with Kids & 3.21 & 3.82 & -0.61 & 0.96 & $.20[.18, .14]$ \\
\hline Young Professionals & 3.63 & 3.13 & 0.50 & 0.93 & $-.15[-.18,-.13]$ \\
\hline Blue-collar Workers & 2.34 & 2.49 & -0.15 & 0.90 & $.09[.06, .11]$ \\
\hline White-collar Workers & 3.67 & 3.72 & -0.05 & 0.86 & $-.02[-.03, .02]$ \\
\hline Young Population & 3.36 & 2.87 & 0.49 & 1.07 & $-.16[-.18,-.13]$ \\
\hline
\end{tabular}

${ }^{\mathrm{a}}$ Kind of community characteristics, a priori categorization. 
${ }^{\mathrm{b}}$ Mean ratings for each characteristic for liberal and conservative participants collapsed into two groups where liberal included anyone responding left of "neutral/moderate" and conservative included anyone responding right of "neutral/moderate."

${ }^{\mathrm{c}}$ Correlation coefficients are not adjusted for demographic variables. Controlling for age does not change the pattern of results. Correlation coefficients adjusting for age are available in the supplementary materials.

\section{Discussion}

Study 2 replicated our findings in Study 1 that political orientation correlates with many community characteristics, even though most of these characteristics are not inherently and necessarily political (e.g., bicycle riding, single family houses). The strongest correlations supported previous research on political enclaves: Liberals preferred communities with more liberal Democrats while conservatives preferred communities with more conservative Republicans (Motyl, 2016). Even when both liberals and conservatives thought the same characteristics were important, they prioritized the characteristics differently. Both liberals and conservatives thought that having many clothing and bookstores were important, but conservatives ranked clothing stores above bookstores, and liberals ranked bookstores above clothing stores. The vast majority (over 90\%) of characteristics were differentially preferred by one ideology or the other. Communities that attract liberals and repel conservatives may feel and look different from communities that attract conservatives and repel liberals.

\section{Study 3a: Overt and Ambient Cues of Community Political Composition}

Studies 1 and 2 demonstrated that liberals and conservatives value community characteristics differently. These studies were correlational and lacked mundane realism because people do not evaluate community characteristics in isolation. We constructed more natural 
descriptions of communities, and experimentally manipulated the presence of politicallydifferentiating characteristics observed in Studies 1 and 2. To determine whether people use these characteristics as cues of communities' political preferences, we also experimentally manipulated the presence of explicit indicators of how liberal or conservative communities are by stating what percentage of residents voted for each political party. Experimentally manipulating the presence of overtly political cues and more ambient characteristics preferred by people on the political left or right permits us to examine whether these ambient cues influence people's intuitions of whether they would belong and like to live in a particular community. If people evaluate communities with ambient cues of a community's politics similarly to those with explicit indicators of the community's politics, that suggests people do not need explicit knowledge about communities' politics to self-segregate.

\section{Method}

Participants. Participants in this study were 1643 people residing in the United States (827 women, 816 men) who registered with YourMorals.org and completed the "Community Comparisons Task." Participants ranged in age from 18 to $88(M=46.73, S D=16.00)$. Of these, 242 identified as conservative, and 1401 identified as liberal. Participants received feedback on how their scores compared to other liberals and conservatives.

Materials and Procedure. Participants read three counterbalanced descriptions of communities that were either all described with explicit information about the politics of the community (e.g., $85 \%$ of the residents voted for Barack Obama) or ambient cues from Studies 1 and 2 that correlate with ideology (e.g., the prevalence of hybrid cars, sport utility vehicles, specific religious organizations, gun stores). All communities were roughly matched in 
population $(376,000+/-1,512)$, crime rate (low), and quality of public schools (very high). For the full text of these descriptions, see the Supplementary Materials.

After reading each description, participants were asked, "How much would you like living in a community like this?” on a scale ranging from 1 (I would not want to live in a community like this) to 6 (I would very much like to live in a community like this). Participants were also provided with a free-response textbox to explain what contributed to their evaluation. ${ }^{3}$

\section{Results}

To analyze the data, we used a 3 (Community Political Leaning: Liberal, Neutral/Moderate, Conservative; within subjects) x 2 (Cue type: Ambient or Explicit; between subjects) x 2 (Participant Political Leaning: Liberal or Conservative; between subjects) mixed ANOVA. All follow-up tests are FDR-corrected planned contrasts. There was a small main effect of participant political orientation, $\left(F(1,1639)=18.23, p<.001, \eta_{\mathrm{G}}{ }^{2}=.006\right)$ such that conservative participants $(M=4.15, S E=0.03)$ gave higher community ratings overall than liberal participants $(M=3.91, S E=0.03), t(1639)=4.27, p<.001,95 \%$ CI $[0.13,0.34]$, Cohen's $\mathrm{d}=0.14$. The main effect of cue type was not significant, $F(1,1639)=3.47, p=.06, \eta_{\mathrm{G}}{ }^{2}=.001$. Community politics significantly affected preferences, $F(1.96,3210.05)^{4}=596.16, p<.001, \eta_{\mathrm{G}}^{2}$ $=.15$, such that participants preferred the liberal community $(M=4.64, S E=0.03)$ over the neutral community $(M=4.34, S E=0.03 ; t(3278)=6.41, p<.001,95 \%$ CI $[0.19,0.42]$, Cohen's $\mathrm{d}=.87$ ), and both the liberal and neutral communities over the conservative community, $M=$

\footnotetext{
${ }^{3}$ See supplemental materials for word clouds of free response data.

${ }^{4}$ The degrees of freedom are adjusted via a Greenhouse-Geisser correction to account for sphericity violations.
} 
$3.10, S E=0.03 ; t(3278)=32.59, \mathrm{p}<.001,95 \%$ CI $[1.43,1.65]$, Cohen's $\mathrm{d}=2.23 ; t(3278)=$ $26.18, \mathrm{p}<.001,95 \%$ CI $[1.12,1.35]$, Cohen's $\mathrm{d}=1.37^{5}$.

All three two-way interactions were significant. The interaction effect between cue type and participant political orientation was significant, but small, $F(1,1639)=5.41, p=.02, \eta_{\mathrm{G}}{ }^{2}=$ .002. Conservatives preferred communities when the community's politics were implied by ambient cues $(M=4.26, S E=0.06)$, than stated explicitly $(M=4.03, S E=0.06), t(1639)=2.27$, $p=.023,95 \% \mathrm{CI}[0.03,0.43]$, Cohen's $\mathrm{d}=0.16$. No differences in preferences across cue type emerged for liberal participants, $t(1639)=0.60, p=.547,95 \%$ CI [-0.06, 0.11], Cohen's $d=$ 0.01 . The interaction between cue type and community type was significant, $F(1.96,3210.05)=$ $63.11, p<.001, \eta_{\mathrm{G}}{ }^{2}=.02$. Participants preferred the liberal community more in ambient condition $(M=4.95, S D=0.05)$, and less in the explicit condition $(M=4.34, S D=0.05)$, $t(4341.29)=7.92, p<.001,95 \%$ CI $[0.46,0.77]$, Cohen's $d=0.06$. Participants preferred the neutral community less in the ambient condition $(M=4.12, S E=0.05)$, and more in the explicit condition $(M=4.56, S E=0.05), t(4341.29)=5.74, p<.001,95 \%$ CI $[0.29,0.60]$, Cohen's d $=$ 0.38 . There was no significant difference in the conservative community, $t(4341.29)=1.79, p=$ $.074,95 \%$ CI [-0.29, 0.01], Cohen's d $=0.31$.

We hypothesized that political orientation would interact with community cues to predict community preferences. Preferences for the communities depended political orientation, $F(1.96$, $3210.05)=727.29, p<.001, \eta_{\mathrm{G}}{ }^{2}=.18$. Liberals preferred the community with liberal cues $(M=$ $5.46, S E=0.04)$ more than conservatives $(M=3.82, S E=0.06), t(4341.29)=21.14, p<.001$, 95\% CI [1.49, 1.79], Cohen's $d=1.70$. Conversely, conservatives preferred the neutral

\footnotetext{
${ }^{5}$ When we run these analyses with all 242 conservatives, and a random sample of 242 liberals, we observe the same mean differences between the community types, $F(1.88,1339.29)=517.29, p<.001, \eta_{\mathrm{G}}{ }^{2}=.27$. For full details, see the supplemental materials.
} 
community $(M=4.54, S E=0.06)$ more than liberals $(M=4.14, S E=0.04), t(4341.29)=5.05, p$ $<.001,95 \%$ CI $[0.24,0.54]$, Cohen's $d=0.30$. Conservatives preferred the community with conservative cues $(M=4.08, S E=0.06)$ more than liberals $(M=2.13, S E=0.04), t(4341.29)=$ $25.20, p<.001,95 \%$ CI $[1.80,2.11]$, Cohen's d $=1.60$. 
Figure 1. Means and $95 \%$ confidence intervals of community desirability ratings.

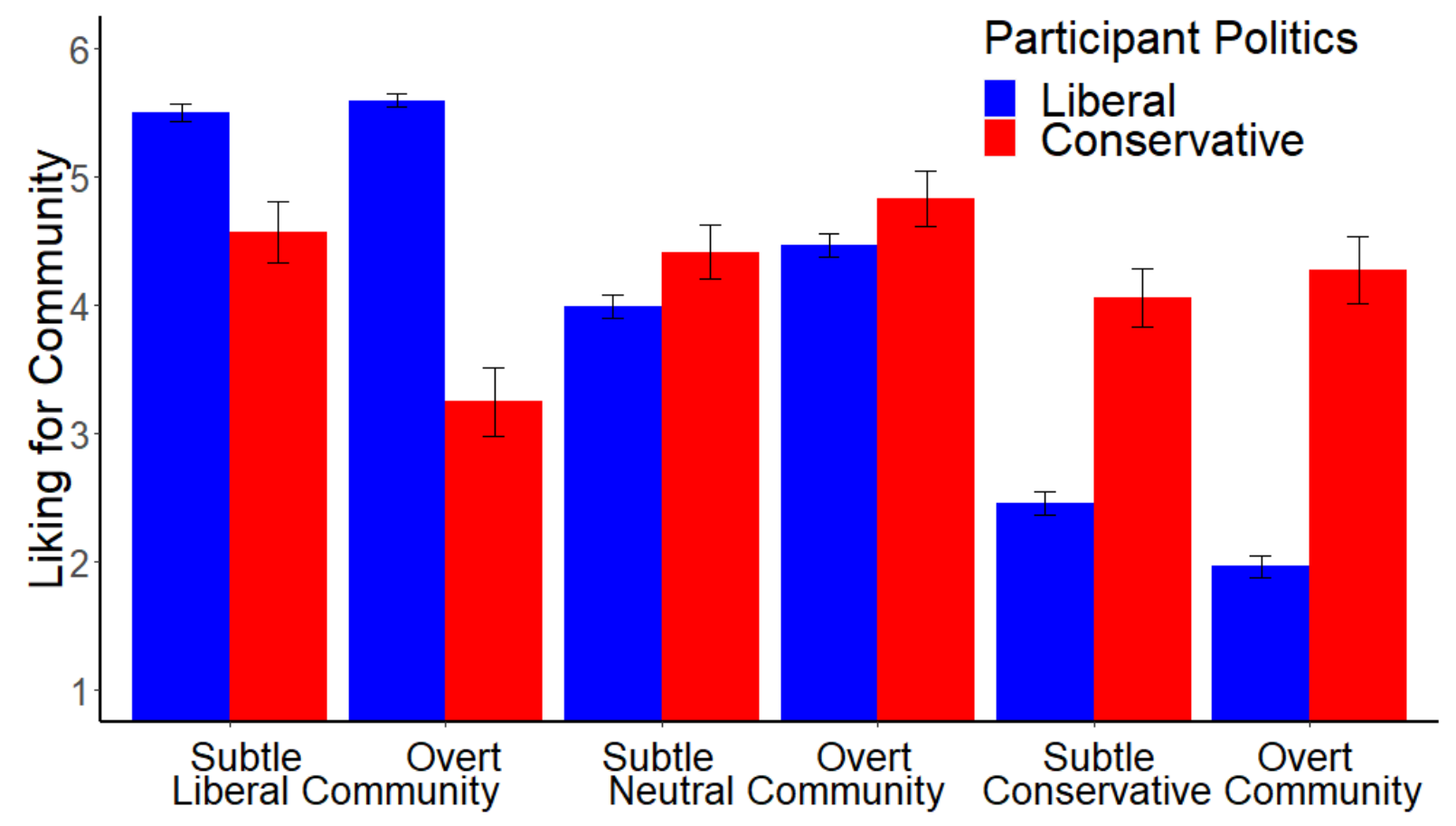

The three-way interaction between community type, cue type, and participant political orientation was significant $F(3.89,3636.78)=31.35, p<.001, \eta_{\mathrm{G}}{ }^{2}=.02$. For a visual depiction of this effect, see Figure 1. Conservatives rated the neutral community as more desirable in the explicit condition $(M=4.74, S E=0.09)$ than the ambient condition $(M=4.33, S E=0.09)$, $t(4341.29)=2.91, p=.004,95 \%$ CI $[0.13,0.77]$, Cohen's $d=0.35$, the conservative community the same regardless of condition $t(4341.29)=1.50, p=.134,95 \% \mathrm{CI}[-0.07,0.49]$, Cohen's $\mathrm{d}=$ 0.16 , and the liberal community as less desirable in the explicit condition $(M=3.16, S E=0.09)$ than the ambient condition $(M=4.48, S E=0.09), t(4341.29)=9.24, p<.001,95 \%$ CI $[1.04$, 1.60], Cohen's $d=0.95$. Liberals rated the moderate community higher in the explicit condition $(M=4.38, S E=0.05)$ than the ambient condition $(M=3.91, S E=0.05), t(4341.29)=7.96, p<$ $.001,95 \%$ CI $[0.36,0.59]$, Cohen's $d=0.39$, the conservative community lower in the explicit 
condition $(M=1.88, S E=0.05)$ than the ambient condition $(M=2.37, S E=0.05), t(4341.29)=$ $8.26, p<.001,95 \%$ CI $[0.37,0.61]$, Cohen's $d=0.42$, and the liberal community equally in the explicit and ambient conditions, $t(4341.29)=1.59, p=.113,95 \% \mathrm{CI}[-0.02,0.21]$, Cohen's $\mathrm{d}=$ 0.12 .

\section{Discussion}

Study 3 a demonstrated that liberals and conservatives preferred politically congenial communities and neutral communities over politically uncongenial communities. This pattern was clearest when cues were explicit, but was similar when cues were more ambient. The similarity of evaluations across explicit and ambient cue conditions may suggest that participants are using one cue type to infer other information. It may also suggest that explicit and more ambient cues are conveying similar information to the participant - that the community would be a place where they would enjoy living, even if the judgment is not necessarily rooted in political fit. Participants may read that a community votes for Democrats and assume that it has a vibrant arts scene and progressive religious organizations. Similarly, participants may read that a community votes for Republicans and assume that it has big box stores and orthodox churches. When people learn that a community has many hybrid cars or SUVs, they may infer that the community's politics are congenial or uncongenial with their own. People may use these ambient cues to infer whether they fit in some communities better than others. Alternately, community politics may serve as one more desirable characteristic, in addition to the pre-existing characteristics.

While liberals showed a clear preference (preferring the liberal community most, the conservative community least, and the moderate community somewhere in between the two), the pattern was murkier for conservatives. This may be due to the liberal skew of our sample. 
Though we had over 200 conservatives in our sample, we had approximately four times as many liberals, and the conservatives in our sample may not be representative of conservatives overall. The conservatives who visit YourMorals.org tend to be more libertarian, and may reject some of the features of prototypical socially conservative communities (e.g., attempts to require school prayer, opposition to recreational marijuana). Despite this, conservative participants in this sample still preferred the conservative community more than liberals and liked the liberal community less than liberals (especially when the community's politics were explicit). Again, while liberals and conservatives preferred different communities, this may be due to some other feature that happens to be related to politics, like lifestyle preferences, opportunities to practice one's preferred hobbies, or particular religious organizations. None of these are inherently political, but certainly correspond with politics (see Studies 1, 2, and 3a).

The city descriptions had unintended consequences. Many participants expressed that they were not fond of such populous cities. While large cities appeal to liberals, conservatives tend to prefer smaller communities (Pew Research Center, 2014). Additionally, some participants worried that they could not afford the communities. We revised our stimuli for a conceptual replication to ensure that these concerns were not distorting our results.

\section{Study 3b: Evaluating Different Communities Via Political Ambience}

In Study $3 b$ we sought to replicate the findings from Study 3a, while adjusting our community descriptions to account for participant feedback. Specifically, Study $3 b$ was nearly identical to Study 3a except for three changes: (a) the population size of the communities was reduced, (b) we stated the cost-of-living was relatively low, and (c) we dropped the cue type manipulation. Study $3 b$ is a close replication and these changes were not expected to change the main pattern of results in Study 3a. 


\section{Method}

Participants. Participants in this study were 1840 people residing in the United States (826 women, 1014 men) who registered with YourMorals.org. After registering, participants who completed the "Community Comparisons Task" were directed to the present study. Of these, 392 identified as conservative, and 1448 identified as liberal. As in previous studies, sample size was determined by including all participants who completed the relevant measures.

Materials and Procedure. The community descriptions from Study 3a were revised in response to participants' feedback. Participants suggested that cities described were too large, so we decreased the population by 300,000 for each community. The new community populations ranged from 74,488 to 78,512. Participants also expressed concerns that the cities described in Study 3a might be prohibitively expensive, so we added information suggesting that the cities had a low unemployment rate, a median income on par with the national average, and a cost-ofliving slightly below the national average.

As in Study 3a, participants indicated how much they would like to live in a community like the one described on a 6-point scale and could explain what contributed to their evaluations. After evaluating each community, participants were debriefed.

To replicate our results from Study 2 and 3a, we conducted a 2 (between subjects; participant political orientation: liberal or conservative) x 3 (within subjects; community politics: liberal, neutral, or conservative community) mixed ANOVA. All follow-up tests are FDRcorrected planned contrasts.

\section{Results}


There was a main effect of community type $F\left(1.88,3452.76^{6}\right)=753.27, p<.001, \eta_{\mathrm{G}}{ }^{2}=$ .15. Participants preferred the liberal community $(M=4.91, S E=0.03)$ to the neutral community $(M=4.36, S E=0.03), t(3676)=14.52, p<.001,95 \%$ CI $[0.46,0.64]$, Cohen's $d=0.82$, the neutral community to the conservative community $(M=3.45, S E=0.03), t(3676)=23.91, p<$ $.001,95 \% \mathrm{CI}[0.82,1.00]$, Cohen's $\mathrm{d}=0.94$, and the liberal to the conservative community, $t(3676)=38.43, p<.001,95 \%$ CI $[1.37,1.55]$, Cohen's $d=1.69$. There was a main effect of political orientation such that conservatives $(M=4.41, S E=0.03)$ rated communities as slightly more attractive overall than liberals $(M=4.08, S E=0.03), t(1838)=6.53, p<.001,95 \% \mathrm{CI}$ $[0.23,0.43]$, Cohen's d $=0.21$.

Figure 2. Means and $95 \%$ confidence intervals of community desirability ratings

\footnotetext{
${ }^{6}$ Degrees of freedom are adjusted using a Greenhouse-Geiser correction to reduce the chance of Type I error. The pattern of results does not change without the correction.
} 


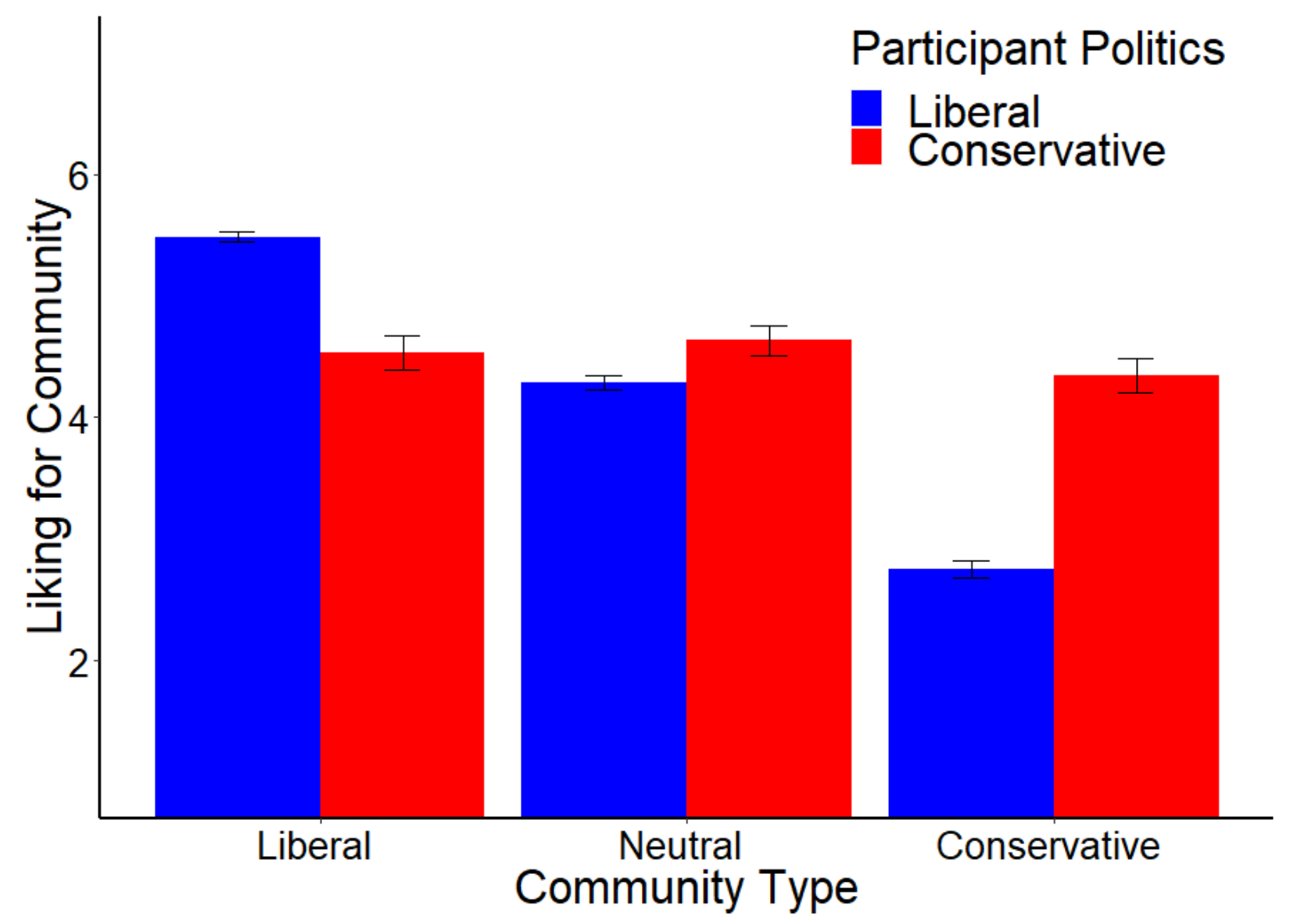

There was a significant interaction between political orientation and community type, $F(1.88,3452.76)=560.01, p<.001, \eta_{\mathrm{G}}^{2}=.12$. To understand the pattern of results, we performed a simple effects analysis. Liberals $(M=5.39, S E=0.04)$ found the community with liberal cues more attractive than conservatives $(M=4.44, S E=0.05), t(4382.52)=14.13, p<$ $.001,95 \%$ CI $[0.82,1.08]$, Cohen's d $=0.95$. Conversely, liberals $(M=4.19, S E=0.04)$ found the neutral community less attractive than conservatives $(M=4.51, S E=0.05), t(4382.52)=$ $5.20, p<.001,95 \%$ CI $[0.22,0.48]$, Cohen's $d=0.29$. The same held true with the conservative community. Liberals $(M=2.66, S E=0.04)$ found the conservative community less attractive than conservatives $(M=4.25, S E=0.05), t(4382.53)=23.75, p<.001,95 \% \mathrm{CI}[1.46,1.72]$, Cohen's d $=1.19$. See Figure 2 .

\section{Discussion}


Study $3 b$ replicated the findings from Study 3a. Our participants preferred communities with ambient cues congenial with their political identity and disliked communities with ambient cues uncongenial with their political identity. These preferences replicated regardless of population size and cost-of-living.

People may be gleaning information about politics from these cues. Many participants noted that the community seemed "too conservative" or "too liberal" for their tastes, despite no explicit mention of the community's political leanings.

\section{Study 4: People Infer Community Political Leanings Using Ambient Cues}

Studies $3 \mathrm{a}$ and $3 \mathrm{~b}$ provide converging evidence that people prefer the communities with ambient cues congruent with their political identity. Study 3a demonstrates that participants differentiate between the liberal and conservative communities, even in the absence of explicit information about the community's political preferences. Study $3 \mathrm{~b}$ replicates the preferences expressed in Study 3a. However, these studies do not provide direct evidence of why ambient political cues elicit discrepant evaluations, and whether these discrepant evaluations contribute to people's tendency to gravitate towards politically congenial communities. Study 4 provides a test of this.

In Study 4, participants imagined living in the liberal or conservative community used in Study $3 b$, and estimated the degree to which people in those communities shared their political and moral values, educational achievement, racial and ethnic background, personality, and religious affiliation. While participants prefer certain community characteristics, and these preferences correlate with political orientation, liberals and conservatives may not be driven by an urge to be around politically similar others. Liberals may gravitate to communities with more ethnic diversity, while conservatives may gravitate to communities with less. This study aimed to 
determine if different preferences along ideological lines are facilitated by perceived political and moral consensus, or for other reasons.

This study also looked at some of the psychological responses to living in these politically congenial or uncongenial communities. Participants indicated how much they thought they would feel a sense of belonging in that community, and how much they thought they would like to continue living in that community, or how much they would like to migrate to a different community.

\section{Method}

Participants. Participants in this study consisted of 282 US residents (76 women, 206 men), from Amazon Mechanical Turk (mTurk). Participants' ages ranged from 18 to 71, with an average of $27.77(S D=8.99)$. Of these, 56 identified as conservatives, and 226 identified as liberals. A priori power analysis based on the effect size difference between liberals and conservatives' evaluations of these specific communities in Study $3 b(d=1.69)$ suggested that a sample size of 28 would be sufficient to achieve $80 \%$ power.

Materials and Procedure. Participants were randomly assigned to read the liberal or conservative community description from Study 3b. After they read the description, they estimated the percentage of people in the community that shared their moral and political values, their ethnic or racial background, their level of education, their religious affiliation, and their personality. They then answered four questions to assess how much they felt they belonged in that community (e.g. "I generally feel like I would belong in this community"), and their desire to migrate away from that community (e.g. "I would like to live somewhere else."). We took the mean of each of these measures to get a score that represented feelings of belonging, and a score that represented desire to migrate. 


\section{Results}

All tests are 2 (Participant political orientation: Liberal or Conservative) x 2 (Community politics: Liberal or Conservative) between-subjects ANOVAs. All follow-up tests are FDRcorrected planned contrasts.

There was no main effect of community politics for perceived educational, personality, or religious consensus (all $p \mathrm{~s}>.14$ ). There was a main effect of community politics for moral and political consensus such that participants perceived greater consensus in the liberal community $(M=63.30, S E=2.06)$ than the conservative community $(M=55.58, S E=2.23),(t(278)=2.54$, $p=.012,95 \%$ CI $[1.74,13.69]$, Cohen's $d=.79)$, and for racial consensus $(t(278)=2.32, p=$ $.02,95 \% \mathrm{CI}[1.31,16.00]$, Cohen's $\mathrm{d}=.23)$, such that participants perceived greater consensus in the conservative community $(M=64.35, S E=2.74)$ than the liberal community $(M=55.70, S E$ $=2.53$ ).

There was no main effect of political orientation for perceived educational, moral and political, personality, or racial consensus (all $p \mathrm{~s}>.19$ ). There was a main effect of political orientation for religious consensus. Liberal participants believed there would be less religious consensus in communities than conservative participants, $t(278)=2.24, p=.026,95 \% \mathrm{CI}[0.95$, 14.83], Cohen's d $=0.31$.

There was no significant interaction between community politics and political orientation for racial consensus. There was a significant interaction between community politics and political orientation for educational $\left(F(1,278)=4.32, p=.04, \eta_{\mathrm{G}}{ }^{2}=.02\right)$, moral and political $\left(F(1,278)=22.74, p<.001, \eta_{\mathrm{G}}^{2}=.08\right)$, personality $\left(F(1,278) .=4.74, p=.03, \eta_{\mathrm{G}}{ }^{2}=.02\right)$, and religious consensus, $F(1,278)=14.56, p<.001, \eta_{\mathrm{G}}{ }^{2}=.05$. 
Despite the significant interaction for educational consensus, none of the pairwise comparisons were significant (all $p \mathrm{~s}>.278$ ). In the interaction for moral and political consensus, liberals believed that more people would share their views in the community with liberal cues, $t(278)=8.24, p<.001,95 \%$ CI $[15.04,29.35]$, Cohen's $d=1.08$. There was no difference between communities for conservatives, $t(278)=1.24, p=.219,95 \%$ CI [-7.70, 21.22], Cohen's $\mathrm{d}=0.36$. In the interaction for personality consensus, Conservatives did not believe that either community was more likely to share their personality, $t(278)=0.13, \mathrm{p}=.900,95 \% \mathrm{CI}[-18.02$, 16.35], Cohen's $d=0.04$. Liberals believed that the liberal community would be more likely to share their personality than the conservative community, $t(278)=5.17, p<.001,95 \%$ CI $[8.04$, 25.06], Cohen's $d=0.68$. In the interaction for religious consensus, there were no differences in community ratings for conservative participants, $t(278)=1.31, p=.289,95 \%$ CI $[-8.54,25.05]$, Cohen's $d=0.10$. Liberals believed that people in liberal communities would be more likely to share their religious beliefs than people in conservative communities, $t(278)=5.96, p<.001$, 95\% CI [10.34, 26.98], Cohen's d =0.80. 
Figure 3. Regression coefficients and standard errors for the consensus types predicting belonging, when all consensus types are entered in the same regression

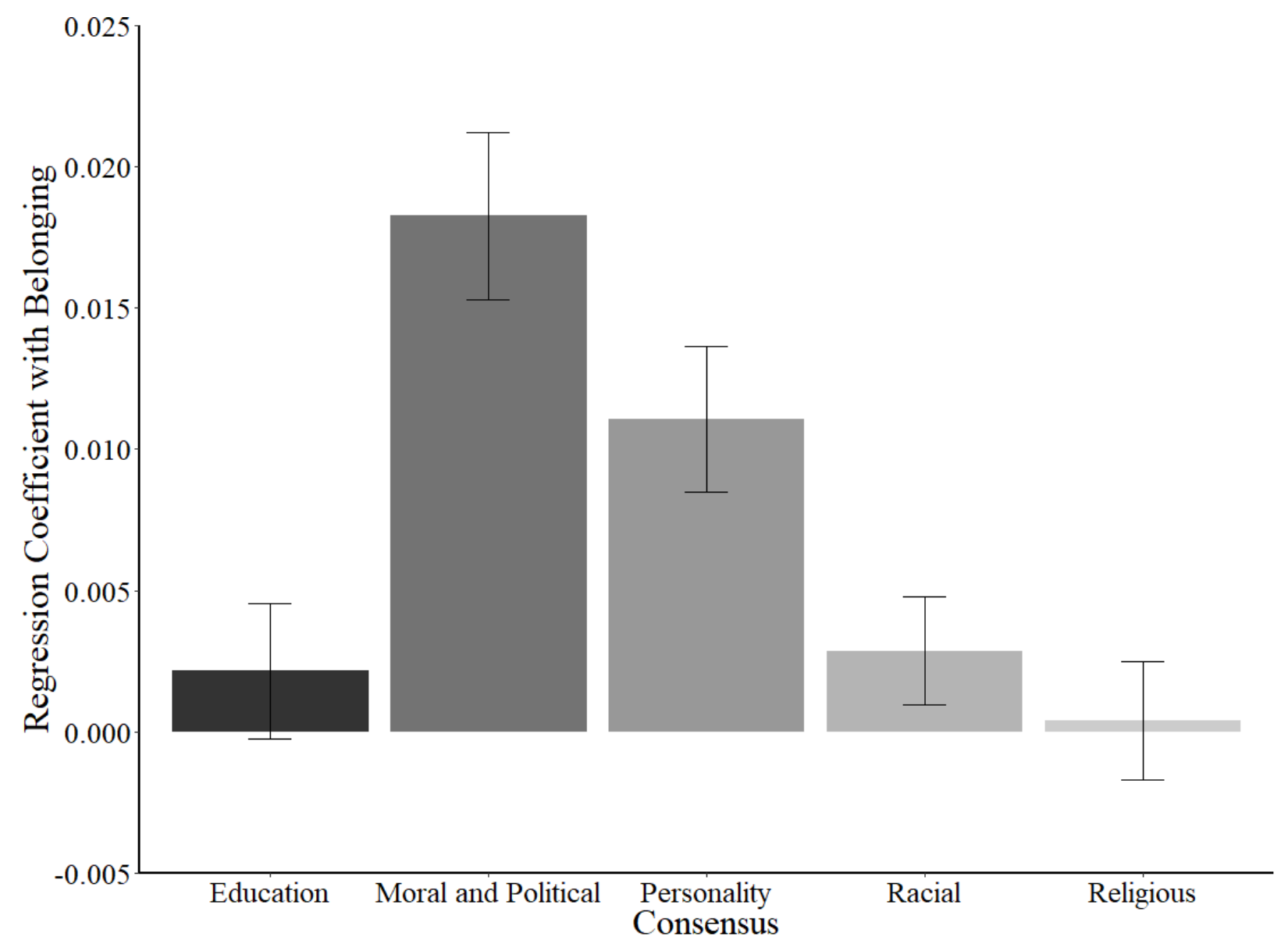

Note. Error bars represent the standard error.

Belonging. There was as an overall effect of community ideology on belonging, such that participants reported a higher sense of belonging in the liberal community than the conservative community, $t(278)=3.47, p=.0006,95 \%$ CI [0.21, 0.77], Cohen's $d=0.77$. This can be fully explained by the liberal-conservative imbalance in our sample, and is qualified by the interaction effect. There was no main effect of personal ideology, $t(278)=1.00, p=.316,, 95 \%$ CI [-0.14, $0.42]$, Cohen's $d=0.15$. The interaction between community and personal politics was significant, $F(1,278)=7.64, p=.006, \eta_{\mathrm{G}}^{2}=.03$. Conservatives did not report any differences in 
belonging, regardless of community, $t(278)=0.40, p=.692,95 \%$ CI $[-0.78,0.58]$, Cohen's $d=$ 0.11 , but liberals in the conservative community reported significantly less belonging than in the liberal community, $t(278)=7.03, p<.001,95 \%$ CI $[0.55,1.22]$, Cohen's $\mathrm{d}=0.94$.

Desire to Migrate. Personal political orientation did not predict desire to migrate, $F(1$, $278)=.69, p=.41,95 \% \mathrm{CI}[-0.45,0.18]$, Cohen's $\mathrm{d}=0.14$. There was a main effect of community such that people assigned to the conservative community expressed more desire to migrate than people in the liberal community, $F(1,278)=16.67, p<.001,95 \%$ CI $[0.34,0.97]$, Cohen's $d=0.80$, but this effect is qualified by a significant interaction effect, $F(1,278)=4.36$, $p=.04, \eta_{\mathrm{G}}{ }^{2}=.02$. Conservatives expressed equal desire to migrate regardless of location $(t(278)$ $=1.11, p=.319,95 \%$ CI $[-0.44,1.09]$, Cohen's $\mathrm{d}=0.32)$, but liberals in a conservative community expressed more desire to migrate than did liberals in a liberal community, $t(278)=$ $6.95, p<.001,95 \%$ CI $[0.61,1.37]$, Cohen's $\mathrm{d}=0.91$.

\section{Discussion}

Study 4 builds upon the results of 3 a and 3b. Liberals perceived the most educational, moral and political, personality, and religious consensus in communities with ambient cues congenial with their personal political orientation, and the least in communities with ambient cues uncongenial with their political orientation. Conservatives perceived the most educational consensus in communities with ambient cues congenial with their political orientation, and the least consensus in communities with ambient cues uncongenial with their political orientation.

Liberals expressed less desire to migrate in communities with ambient cues congenial with their personal political identity, and more desire to migrate in communities with ambient cues uncongenial with their political orientation. 


\section{Study 5: People Selectively Navigate their Communities}

Building upon the self-reported community preferences of liberals and conservatives in Studies 1-4, we conducted a behavioral study to determine whether self-reported preferences map onto actual behavior. Specifically, liberals and conservatives can be found in most, if not all, communities, regardless of whether they want to live in those communities. Therefore, in Study 5, we examined whether liberals and conservatives navigate their real communities in selective ways where they are more likely to visit parts of communities that are more appealing to people with their political leanings. To do so, we visited the parking lots attached to places that liberals and conservatives showed a preference for/against in Studies 1 and 2. If liberals' and conservatives' preferences led them to different spaces, cars with liberal or conservative bumper stickers should be disproportionately found in different spaces with politically congenial cues within communities. For example, more liberal bumper stickers and fewer conservative bumper stickers should be found at Whole Foods and Unitarian Universalist churches than at Wal-Marts and Evangelical churches, regardless of how liberal or conservative that specific community is. This study will allow us to see whether people act on their stated preferences and gravitate more towards the features of communities that their liberal and conservative brethren previously defined as congenial to those on the left or right.

\section{Methods}

Materials and Procedure. We coded political bumper stickers on cars parked in several locations in central Virginia (Staunton, Waynesboro, Charlottesville-proper, and Albemarle). Bumper stickers were coded for their political message, and whether they were supporting or attacking this liberals or conservatives. Stickers were placed in one of four categories: proliberal, pro-conservative, anti-liberal, and anti-conservative. A pro-liberal sticker might say 
"proud liberal," while an anti-liberal sticker might say “Annoy a liberal: Use facts and logic.” A pro-conservative sticker might say "Remember in November: Vote Conservative," while an anticonservative sticker might say “Annoy a conservative: Think for yourself.” Because past research shows that liking for one's own political group is correlated with hatred for politically dissimilar others (Crawford et al., 2013; Crawford \& Botchwey, 2017; Iyengar \& Westwood, 2015), we categorized bumper stickers attacking liberals or affirming conservatives as "conservative", and stickers attacking conservatives or affirming liberals as "liberal."

We coded 372 bumper stickers from cars in parking lots in four different communities which varied in their political liberalism, as approximated from the vote percentage for President Obama in 2012, from $28 \%$ to $76 \%$.

We coded the locations where these bumper stickers were found, including parking lots of retail stores (e.g. Wal-Mart, Target), religious buildings (e.g., Evangelical Churches, Unitarian Universalist Churches), coffee shops (e.g., Starbucks, Milli Joe's), grocery stores (e.g. Whole Foods, Kroger), and more.

These locations were divided into three categories based upon the preferences expressed in Studies 1 and 2: liberal, conservative, or neutral. Liberal locations were locations that liberals rated higher in Studies 1 and 2 (organic food stores and bookstores), and conservative locations the conservatives rated higher in Studies 1 and 2 (Wal-Mart and conservative churches). 


\section{Results}

Table 4. Bumper sticker frequencies by space

\section{Bumper Sticker}

\begin{tabular}{lcc}
\cline { 2 - 3 } Space & Liberal & Conservative \\
\hline Liberal Space & $127(63.50 \%)$ & $41(23.84 \%)$ \\
Conservative Space & $73(36.50 \%)$ & $131(76.44 \%)$
\end{tabular}

The overall model for political message and parking lot politics was significant $\chi^{2}(1, N=$ $372)=57.15, p<.001, V=.39$. Conservative spaces had a higher proportion of conservative bumper stickers to liberal stickers.

\section{Discussion}

Study 5 is a behavioral replication of the self-reported preferences in Studies 1 through 4 . Within communities, peopled navigate towards the spaces that were deemed politicallycongenial in Studies 1 and 2. Liberals were disproportionately likely to be at local bookstores, local fair-trade cafes, Unitarian Universalist churches, and Whole Foods, and conservatives were disproportionately likely to be at Evangelical Protestant churches, gun stores, big box stores, and Wal-Marts. 


\section{General Discussion}

Across five studies, liberals and conservatives expressed different community preferences. In Studies 1 and 2, liberals and conservatives expressed different preferences for community characteristics. In Studies 3a and 3b, liberals preferred communities with liberal characteristics, and conservatives preferred communities with conservative characteristics, even in the absence of explicit information about the communities' political leanings. Evaluations of communities in Study 3a did not differ based on whether the cues were explicit or subtle, suggesting that people may use ambient cues to estimate a community's politics. In Study 4, liberals and conservatives believed that residents of politically congenial communities were more morally and politically similar. This perceived similarity predicted more belonging and less desire to migrate. Study 5 showed that liberals and conservatives navigate to different spaces within communities. These studies are consistent with our hypothesis: Liberals and conservatives prefer different communities, and they use ambient cues in communities to navigate those communities in ways that promote political segregation. This is consistent with previous research that shows that people self-segregate using ambient cues of personality (e.g., Gosling et al., 2002; Jokela, 2009; Jokela et al., 2015; Rentfrow et al., 2008), religion (Bilewicz et al., 2013; Ribak-Rosenthal et al., 1994; Schmitt et al., 2010), and sexual orientation (e.g., Lick, Tornello, Riskind, Schmidt, \& Patterson, 2012). Studies 3a, 3b, and 4 suggest that liberals may be more motivated to self-segregate using these more ambient cues than conservatives. Unfortunately, the liberal skew of our samples makes it difficult to draw any conclusions.

These studies have their limitations. While many of the samples are large and come from different sources, none are representative. Additionally, Study 5, while behavioral, contains data 
from a relatively small area. This research should be replicated using different sampling procedures and methodology.

This research examines reactions to static communities, but communities change. Shops open and close, and demographics shift over time. Future studies should examine whether changes in community cues, for example a Whole Foods opening, or a Wal-Mart closing, influence residents' sense of belonging and desire to migrate. It should also examine whether cues influence behavior. Exposure to politically congenial or uncongenial ambient cues may affect feelings of belonging, and through that, attitudes and behavior towards politically similar or dissimilar others (e.g., Chopik \& Motyl, 2016).

Liberals and conservatives' preferences allow them to navigate to liberal and conservative communities without explicit information about the community's politics. Ambient political cues make it easier for people, even those lacking political knowledge, to migrate into political enclaves (Bishop \& Cushing, 2008; Gimpel \& Hui, 2015; Motyl, 2014; Motyl et al., 2014). There, they are surrounded by people who agree with them, while people who disagree with them are motivated to leave for more politically congenial pastures.

With politically similar people moving in, and politically dissimilar people moving out, political enclaves form. Reliance on community cues to determine political fit may partially account for why Americans are politically self-segregating into red and blue spaces (Bishop \& Cushing, 2008). As people move towards communities where they feel that they fit, they selfsegregate. Curiously, this political self-segregation need not even be inherently political; it could be due to people preferring some other community features that incidentally correlate with politics (e.g., wanting to live in a single-family home, or wanting to use public transportation). Regardless of whether this process is explicitly rooted in politics or something broader about 
lifestyle preferences, the end result is the same -- people end up in communities where they are unlikely to encounter people with dissimilar political views. When there is an encounter, it may go poorly, worsening intergroup attitudes (see Allport, Clark, \& Pettigrew, 1954; Graf, Paolini, \& Rubin, 2014; Paolini, Harwood, \& Rubin, 2010; Pettigrew \& Tropp, 2006). These segregated areas may serve as echo chambers, where residents are relatively free from information that challenges their beliefs. Echo chambers like these have formed online. Liberal and conservative blogs rarely reference one-another, users seeking news online use politically congenial sources, and political discussions on Twitter are generally divided along political lines (Adamic \& Glance, 2005; Barberá, Jost, Nagler, Tucker, \& Bonneau, 2015; Garrett, 2009; Nahon \& Hemsley, 2014).

In these echo chambers, bipartisan political discussion becomes difficult, and prejudice and even violence against politically dissimilar others may proliferate (Motyl, Rothschild, \& Pyszczynski, 2009; Pyzczynski, Henthorn, Motyl, \& Gerow, 2010; Westfall, Van Boven, Chambers, \& Judd, 2015). In politically segregated groups, political beliefs become more extreme. Judges on politically homogeneous panels come to more extreme rulings than judges on heterogeneous panels (Sunstein, 2009), and misinformation spreads faster and reaches larger audiences in homogeneous networks (Del Vicario et al., 2016; Sunstein \& Vermule, 2009; van Prooijen, Krouwell, \& Pollet, 2015).

We do not just segregate into red and blue states; we segregate into red and blue communities, and even red and blue churches, restaurants, and shops. While the average American may not be politically knowledgeable (Delli Carpini, 2000; Delli Carpini et al., 1992; Frimer, et al., 2017), people can segregate by ambient cues to navigate to places where others share their views, and away from places where others do not, even if doing so is unintentional. 
Americans' ability to move to politically homogenous areas (Bishop et al., 2008; McDonald, 2011; Motyl, 2016) in the absence of political knowledge may be facilitated by ambient cues in the environment. These cues and our reactions to them facilitate the formation of the politically segregated country that America has become. 


\section{References}

Abramowitz, A. I., \& Webster, S. (2016). The rise of negative partisanship and the nationalization of US elections in the 21st century. Electoral Studies, 41, 12-22.

Adamic, L. A., \& Glance, N. (2005, August). The political blogosphere and the 2004 US election: divided they blog. In Proceedings of the 3rd international workshop on Link discovery (pp. 36-43). ACM.

Allport, G. W. (1955). The nature of prejudice. Cambridge, Mass: Addison-Wesley Pub. Co.

Barberá, P., Jost, J. T., Nagler, J., Tucker, J. A., \& Bonneau, R. (2015). Tweeting from left to right: Is online political communication more than an echo chamber? Psychological Sjcience, 26(10), 1531-1542.

Bilewicz, M., \& Klebaniuk, J. (2013). Psychological consequences of religious symbols in public space: Crucifix display at a public university. Journal of Environmental Psychology, 35, 10-17.

Bishop, B., \& Cushing, R. (2008). The big sort. Why the Clustering of America is Tearing Us Apart. NY: Houghton Mifflin.

Byrne, D., Clore, G. L., \& Smeaton, G. (1986). The attraction hypothesis: Do similar attitudes affect anything? Journal of Personality and Social Psychology, 51(6), 1167-1170.

Carney, D. R., Jost, J. T., Gosling, S. D., \& Potter, J. (2008). The secret lives of liberals and conservatives: Personality profiles, interaction styles, and the things they leave behind. Political Psychology, 29(6), 807-840.

Chinni, D., \& Gimpel, J. (2011). Our patchwork nation: the surprising truth about the "real" America. Penguin. 
Chopik, W. J., \& Motyl, M. (2016). Ideological fit enhances interpersonal orientations. Social Psychological and Personality Science, 7(8), 759-768.

Crawford, G., \& Botchwey, G. (2017). Conflict, collusion and corruption in small-scale gold mining: Chinese miners and the state in Ghana. Commonwealth \& Comparative Politics, $55(4), 444-470$.

Crawford, J., Modri, S., \& Motyl, M. (2013). Bleeding-heart liberals and hard-hearted conservatives: Subtle political dehumanization through differential attributions of human nature and human uniqueness traits. Journal of Social and Political Psychology, 1(1), 86104.

Del Vicario, M., Bessi, A., Zollo, F., Petroni, F., Scala, A., Caldarelli, G., ... \& Quattrociocchi, W. (2016). The spreading of misinformation online. Proceedings of the National Academy of Sciences, 113(3), 554-559.

Delli Carpini, M. X. (2000). In search of the informed citizen: What Americans know about politics and why it matters. The Communication Review, 4(1), 129-164.

Delli Carpini, M. X., \& Keeter, S. (1992). The public's knowledge of politics. Public Opinion, the Press, and Public Policy, ed. J. David Kennamer (Westport, CT: Praeger, 1992), 19-40.

Dixon, J., \& Durrheim, K. (2003). Contact and the ecology of racial division: Some varieties of informal segregation. British Journal of Social Psychology, 42(1), 1-23.

Frimer, J. A., Skitka, L. J., \& Motyl, M. (2017). Liberals and conservatives are similarly motivated to avoid exposure to one another's opinions. Journal of Experimental Social Psychology, 72, 1-12.

Garrett, R. K. (2009). Echo chambers online?: Politically motivated selective exposure among Internet news users. Journal of Computer-Mediated Communication, 14(2), 265-285. 
Gimpel, J. G., \& Hui, I. S. (2015). Seeking politically compatible neighbors? The role of neighborhood partisan composition in residential sorting. Political Geography, 48, 130142.

Gimpel, J. G., \& Hui, I. (2017). Inadvertent and intentional partisan residential sorting. The Annals of Regional Science, 58(3), 441-468.

Gimpel, J. G., \& Schuknecht, J. E. (2002). Reconsidering political regionalism in the American states. State Politics \& Policy Quarterly, 2(4), 325-352.

Gosling, S. D., Ko, S. J., Mannarelli, T., \& Morris, M. E. (2002). A room with a cue: Personality judgments based on offices and bedrooms. Journal of Personality and Social Psychology, $82(3), 379$.

Graf, S., Paolini, S., \& Rubin, M. (2014). Negative intergroup contact is more influential, but positive intergroup contact is more common: Assessing contact prominence and contact prevalence in five Central European countries. European Journal of Social Psychology, $44(6), 536-547$.

Hoffman, K. M., Trawalter, S., \& Waytz, A. (2016, March). On the importance of public space for perpetuating (or reducing) social inequity. Oral presentation given at the University of Virginia Arts and Sciences Huskey Research Exhibition, Charlottesville, VA.

Iyengar, S., Sood, G., \& Lelkes, Y. (2012). Affect, Not Ideology: A Social Identity Perspective on Polarization. Public Opinion Quarterly, 76(3), 405-431.

Iyengar, S., \& Westwood, S. J. (2015). Fear and loathing across party lines: New evidence on group polarization. American Journal of Political Science, 59(3), 690-707.

Jokela, M. (2009). Personality predicts migration within and between US states. Journal of Research in Personality, 43(1), 79-83. 
Jokela, M., Bleidorn, W., Lamb, M. E., Gosling, S. D., \& Rentfrow, P. J. (2015). Geographically varying associations between personality and life satisfaction in the London metropolitan area. Proceedings of the National Academy of Sciences, 112(3), 725-730.

Jokela, M., Elovainio, M., Kivimäki, M., \& Keltikangas-Järvinen, L. (2008). Temperament and migration patterns in Finland. Psychological Science, 19(9), 831-837.

Keating, J., Van Boven, L., \& Judd, C. M. (2016). Partisan underestimation of the polarizing influence of group discussion. Journal of Experimental Social Psychology, 65, 52-58.

Lick, D. J., Tornello, S. L., Riskind, R. G., Schmidt, K. M., \& Patterson, C. J. (2012). Social climate for sexual minorities predicts well-being among heterosexual offspring of lesbian and gay parents. Sexuality Research and Social Policy, 9(2), 99-112.

Mackie, D. M. (1986). Social identification effects in group polarization. Journal of Personality and Social Psychology, 50(4), 720.

Mackinnon, S. P., Jordan, C. H., \& Wilson, A. E. (2011). Birds of a feather sit together: Physical similarity predicts seating choice. Personality and Social Psychology Bulletin, 37(7), 879-892.

McCarty, N., Poole, K. T., \& Rosenthal, H. (2016). Polarized America: The dance of ideology and unequal riches. MIT Press.

McDonald, I. (2011). Migration and sorting in the American electorate: Evidence from the 2006 Cooperative Congressional Election Study. American Politics Research, 39(3), 512-533.

McPherson, M., Smith-Lovin, L., \& Cook, J. M. (2001). Birds of a feather: Homophily in social networks. Annual Review of Sociology, 27(1), 415-444.

Motyl, M. (2016). Liberals and conservatives are (geographically) dividing. In Social Psychology of Political Polarization (pp. 17-47). Routledge. 
Motyl, M., Iyer, R., Oishi, S., Trawalter, S., \& Nosek, B. A. (2014). How ideological migration geographically segregates groups. Journal of Experimental Social Psychology, 51, 1-14.

Mummolo, J., \& Nall, C. (2017). Why partisans do not sort: The constraints on political segregation. The Journal of Politics, 79(1), 45-59.

Nahon, K., \& Hemsley, J. (2014). Homophily in the guise of cross-linking: Political blogs and content. American Behavioral Scientist, 58(10), 1294-1313.

Paolini, S., Harwood, J., \& Rubin, M. (2010). Negative intergroup contact makes group memberships salient: Explaining why intergroup conflict endures. Personality and Social Psychology Bulletin, 36(12), 1723-1738.

Pettigrew, T. F., \& Tropp, L. R. (2006). A meta-analytic test of intergroup contact theory. Journal of Personality and Social Psychology, 90(5), 751.

"Political Polarization in the American Public" (2014, June 12). Pew Research Center. Retrieved January 15, 2015 from http://www.people-press.org/2014/06/12/political-polarization-inthe-american-public/.

Purdie-Vaughns, V., Steele, C. M., Davies, P. G., Ditlmann, R., \& Crosby, J. R. (2008). Social identity contingencies: how diversity cues signal threat or safety for African Americans in mainstream institutions. Journal of personality and social psychology, 94(4), 615.

Pyszczynski, T., Henthorn, C., Motyl, M., \& Gerow, K. (2010). Is Obama the Anti-Christ? Racial priming, extreme criticisms of Barack Obama, and attitudes toward the 2008 US presidential candidates. Journal of Experimental Social Psychology, 46(5), 863-866.

Rentfrow, P. J., Gosling, S. D., \& Potter, J. (2008). A theory of the emergence, persistence, and expression of geographic variation in psychological characteristics. Perspectives on Psychological Science, 3(5), 339-369. 
Ribak-Rosenthal, N., \& Russell, T. T. (1994). Dealing with religious differences in December: A school counselor's role. Elementary School Guidance \& Counseling, 28(4), 295-301.

Schmitt, M. T., Davies, K., Hung, M., \& Wright, S. C. (2010). Identity moderates the effects of Christmas displays on mood, self-esteem, and inclusion. Journal of Experimental Social Psychology, 46(6), 1017-1022.

Sunstein, C. R. (2002). The law of group polarization. Journal of political philosophy, 10(2), 175-195.

Sunstein, C. R., \& Vermeule, A. (2009). Conspiracy theories: Causes and cures. Journal of Political Philosophy, 17(2), 202-227.

Van Prooijen, J. W., Krouwel, A. P., \& Pollet, T. V. (2015). Political extremism predicts belief in conspiracy theories. Social Psychological and Personality Science, 6(5), 570-578.

Westfall, J., Van Boven, L., Chambers, J. R., \& Judd, C. M. (2015). Perceiving political polarization in the United States: Party identity strength and attitude extremity exacerbate the perceived partisan divide. Perspectives on Psychological Science, 10(2), 145-158. 